\title{
CONDIÇÕES DE TRABALHO COMO PRESSUPOSTO PARA VALORIZAÇÃO PROFISSIONAL DOCENTE: O DOCUMENTO-REFERÊNCIA DA II CONAE EM FOCO
}

\author{
Andréia Nunes Militão ${ }^{1}$, Fabio Perboni ${ }^{1}$, Silvio Cesar Nunes Militão ${ }^{2}$ \\ ${ }^{1}$ Discente do Doutorado em Educação - PPGE - FCT/UNESP. Docente do Departamento de Educação - FCT/UNESP. \\ Email: andreianmilitao@terra.com.br.FAPESP
}

\section{RESUMO}

O presente trabalho centra-se, particularmente, na discussão das condições de trabalho docente assumindo que a sua garantia é pressuposto para a melhoria da educação. O texto em tela objetiva discutir, a partir da perspectiva freireana, os elementos necessários para se garantir a valorização de tal categoria profissional. Para tanto, valeu-se de levantamento e análise bibliográfica e documental sobre a temática em abordagem. Após uma análise conceitual e contemporânea acerca das condições de trabalho do professor, examina-se o lugar das "condições de trabalho docente" no Documento-Referência (DR) da II Conferencia Nacional da Educação (CONAE/2014), ancorando-se no pensamento de Paulo Freire e nas suas contribuições afetas a tal debate. Conclui que as proposições e estratégias elaborados para subsidiar os debates das conferências de educação pouco avançam em questões centrais, em especial, em relação à melhoria das condições de trabalho.

Palavras-chave: Condições de trabalho. CONAE. Documento-Referência. Professor. Valorização profissional.

\section{INTRODUÇÃO E OBJETIVO}

Temática em evidência na atualidade, a valorização dos profissionais da educação foi amplamente tratada por Paulo Freire em suas obras. Nesse sentido, o texto em tela objetiva discutir, a partir da perspectiva freireana os elementos necessários para se garantir a valorização desses profissionais, detendo-se mais especificamente na análise das condições de trabalho. Analisando para isso o documento referencia da CONAE/2014

A polissemia presente na adoção do termo "condições de trabalho" pode ser localizada na literatura acadêmica que trata da temática. Verifica-se uma profusão de terminologias, tais como a utilizada por Migliavacca (2010) "condições de trabalho do professor", enquanto que Oliveira e Assunção (2010) preferem "condições de trabalho docente".

Para Oliveira e Assunção (2010, p.01), apoiadas na vertente marxista o vocábulo condições de trabalho "designa o conjunto de recursos que possibilitam a realização do trabalho, envolvendo as instalações físicas, os materiais e insumos disponíveis, os equipamentos e meios de realização das atividades e outros tipos de apoio necessários". No entanto, as autoras alertam que as relações de emprego estabelecidas no local do trabalho também compõem as condições 
adequadas para o exercício profissional, aspecto geralmente obliterado seja nas formulações dos planos de carreira, seja nas reivindicações dos trabalhadores da área educacional.

Ao adotar o termo "condições de trabalho do professor", Migliavacca (2010, p. 01) ressalta que "A expressão alude aos aspectos sociais, políticos, culturais e educacionais que, em um período histórico dado, delimitam o marco estrutural em que se desenvolve o processo de trabalho do professor".

Hypólito (2012, p. 211) defende que "as condições de produção do trabalho de ensinar como fator determinante do fracasso escolar tem sido especialmente negligenciado pelas políticas educacionais". Para o autor há vários fatores que abarcam as condições de trabalho no âmbito das escolas públicas, que por sua vez interferem na atuação dos profissionais. Dentre estes, o autor destaca "formação; carreira, remuneração e formas de contratação; processo de trabalho intensificação, cargas de trabalho, tempos, características das turmas (aspectos materiais e emocionais); condições físicas e materiais do trabalho; dentre outros" (HYPOLITO, 2012, p. 211).

A esse debate, Paro (2012, p. 588-89) acrescenta que

[...] acima do próprio fato de tratar-se de um trabalho que se processa no âmbito da produção não material, é que se trata de uma relação entre sujeitos, e que o próprio objeto de trabalho (aquilo que se transforma em produto durante o processo de produção), ou seja, o educando (que transforma sua personalidade viva, à medida que se educa), tem como característica intrínseca e inalienável o fato de ser um sujeito. Essa condição deve ser determinante do trabalho do professor, que tem pela frente não um simples objeto, mas um sujeito que, como ele mesmo, trabalha nesse processo como coprodutor de sua educação.

Robalino (2012, p. 317) adiciona um novo elemento nessa discussão, quer seja pensar "o entorno físico do âmbito laboral”. De modo geral, esse aspecto é pouco considerado nas carreiras. A maioria dos planos de cargos e carreira não valorizam com gratificações aqueles profissionais que trabalham nesses espaços, embora seja determinante pela maioria dos profissionais para escolher o local de trabalho:

Um exercício pleno e satisfatório da docência precisa da convergência harmônica nos espaços laborais e de condições favoráveis associadas a aspectos como: a) conhecimento suficiente para cumprir a função (formação inicial e formação contínua); b) entorno físico do âmbito laboral apropriado (infraestrutura, equipamento, facilidade de acesso aos centros de trabalho); c) regulamentações que facilitem e apóiem o cumprimento de sua função e promovam a utilidade no exercício da docência; e d) condições sociais e culturais adequadas nas escolas (trabalho em equipe, 
atenção às necessidades e diversidades de cada membro da comunidade educativa etc).

Partindo da premissa de que a escola não é apenas um espaço físico, mas que envolve as relações que se estabelecem entre os diversos sujeitos que percorrem esse espaço, que Freire durante a sua gestão como secretário municipal de educação da cidade de São Paulo se preocupou com as condições de trabalho a que eram submetidos todos os profissionais que atuavam nas escolas públicas como daqueles que eram seus usuários.

Se não apenas construirmos mais salas de aulas mas também as mantemos bem-cuidadas, zeladas e limpas, alegres, bonitas, cedo ou tarde a própria boniteza do espaço requer outra boniteza: a do ensino competente, a da alegria de aprender, a da imaginação criadora tendo a liberdade de exercitar-se, a da aventura de criar (FREIRE, 2006, p. 22).

Freire (2006, p. 33) questiona: "como ensinar e aprender com alegria numa escola cheia de poças d'água, com a fiação ameaçadoramente desnuda, com a fossa entupida, inventando enjôo e náusea?".

Nesse sentido, sua preocupação se insere muito mais nas condições objetivas do trabalho docente, tida como pré-condição para que outros fatores possam ser levados em consideração e aprimorados na escola:

[...] não podemos falar das metas educativas sem nos referirmos às condições materiais das escolas. É que elas não são apenas "espírito", mas "corpo" também. A prática educativa cuja política nos cabe traçar, democraticamente, se dá na concretude da escola, por sua vez situada e datada e não na cabeça das pessoas (FREIRE, 2006, p. 33, grifos nossos).

Observando as condições objetivas das escolas, Robalino (2012, p. 318) apoiada em dados de pesquisa da UNESCO (2005), ressalta que "as condições de trabalho são entendidas como o conjunto de dimensões sociais, pessoais e físicas que convergem nos ambientes laborais e têm efeitos explícitos ou implícitos no desempenho".

O autor aponta ainda que as condições de trabalho se referem a muitos outros aspectos, que fazem do trabalho do professor uma atividade diferente de outras formas de atuação profissional por sua especificidade de não se tratar de produção de bens materiais, mantendo-se no âmbito das interações pessoais de crianças e jovens em formação. 
Na perspectiva de Paro (2012), para que o trabalho educativo seja de qualidade é essencial se considerar as condições de espaço e de tempo oferecidos ao professor superando elementos tradicionais tidos como imputáveis em nossa concepção de escola, como a

[...] tradicional maneira de dispor turmas em "classes" com 30 ou 40 alunos, sentados enfileirados e "assistindo" às aulas de maneira mais ou menos formal, certamente exigirá um edifício escolar organizado de forma a atender, confortavelmente, vários grupos pequenos de estudantes que participam das atividades educativas de maneira mais livre e espontânea (PARO, 2012, p. 606).

Paulo Freire é categórico ao afirmar que as condições materiais são imprescindíveis para o desempenho adequado das funções de trabalho:

Condições materiais condignas - salários decentes, as escolas conservadas, reparadas em tempo, agilização das medidas burocráticas indispensáveis ao bom funcionamento das escolas. Respeito aos educadores, aos educandos, a todos. Como, porém, revelar respeito às crianças, aos educadores e à educadoras, à direção da escola, às merendeiras, aos zeladores, aos país, às mães, à comunidade local, se as escolas vão se deteriorando dia a dia, ameaçando a saúde, a paz de todos, apesar da insistência com que as diretoras solicitam durante meses o indispensável reparo da escola? (FREIRE, 2006, p. 33).

\section{METODOLOGIA}

O presente trabalho centra-se, particularmente, na discussão das condições de trabalho docente. Para tanto, valeu-se de levantamento e análise bibliográfica e documental sobre a temática em abordagem.

Após uma análise conceitual e contemporânea acerca das condições de trabalho docente, examina-se o lugar das "condições de trabalho docente" no Documento-Referência (DR) da II Conferencia Nacional da Educação (CONAE/2014), ancorando-se no pensamento de Paulo Freire e nas suas contribuições afetas a tal debate.

\section{RESULTADOS}

O DR da CONAE/2014 foi elaborado pelo Fórum Nacional de Educação (FNE), órgão composto por 45 entidades de representação nacional da educação pública e privada, empresários, sociedade civil e de gestores públicos. Totalizando 96 páginas, o DR contém sete eixos e inova no formato ao trazer, após apresentação breve de cada tema, proposições (estas em 
maior número) e estratégias com a indicação das responsabilidades e co-responsabilidades entre os entes federados (União, Estados/DF e municípios).

Elegemos para analisar nesse texto o eixo $\mathrm{VI}$, que trata especificamente da "Valorização dos Profissionais da Educação: formação, remuneração, carreira e condições de trabalho", em especial, por entendermos que a melhoria das condições de trabalho, em especial, a delimitação de jornada e o aumento salarial são pouco tratados ou mesmo estão ausentes no DR. Conforme aponta o documento supracitado,

O Brasil tem uma grande dívida com os profissionais da educação, particularmente no que se refere à sua valorização. Para reverter essa situação, as políticas de valorização não podem dissociar formação, salários justos, carreira e desenvolvimento profissional. É preciso assegurar condições de trabalho e salários justos equivalentes com outras categorias profissionais de outras áreas que apresentam o mesmo nível de escolaridade e o direito ao aperfeiçoamento profissional contínuo (BRASIL, 2012, p. 80).

As proposições e estratégias do eixo VI foram divididas em duas temáticas: 1) profissionais da Educação: formação inicial e continuada (34 proposições), e 2) valorização: plano de carreira, jornada de trabalho e remuneração (13 proposições).

A discussão acadêmica em torno da importância de se garantir condições adequadas para o exercício do trabalho docente não encontra ressonância no DR da CONAE/2014. Embora conste no título do eixo seis que a valorização dos profissionais passa, necessariamente, pela garantia das condições de trabalho, esse aspecto pouco foi abordado no referido documento.

Paro (2012) coloca que centrar a discussão da melhoria da qualidade apenas no aspecto da formação oblitera as reais causas dos problemas educacionais e, no nosso entender, responsabiliza os profissionais por problemas decorrentes das políticas públicas de âmbito geral.

Concentrar a atenção sobre a formação dos profissionais da educação como o problema mais importante da qualidade do ensino fundamental, como costumam fazer, em seu discurso, as autoridades governamentais responsáveis pelos sistemas de ensino, pode ser uma boa forma de obnubilar os reais determinantes do fracasso escolar, ou seja, as condições objetivas de trabalho (PARO, 2012, p. 598).

O autor sugere ainda que esta postura não se dá ao acaso, mas é resultado de um posicionamento político para desresponsabilizar os gestores públicos.

A insistência com que os administradores dos sistemas de ensino procuram culpar a qualificação do professor pela baixa qualidade da educação escolar tem funcionado como álibi para 0 insuficiente esforço 
governamental no fornecimento de condições objetivas de trabalho que possibilitem a realização de uma educação fundamental de qualidade (PARO, 2012, p. 610).

\section{DISCUSSÃO}

Para analisar o documento separarmos suas 47 proposições em cinco categorias, de acordo com a temática da proposta: formação inicial, formação continuada, remuneração, carreira e condições de trabalho. Cabe destacar, que uma mesma proposição poderia abarcar mais de uma categoria, portanto, chegamos a um total de 67 proposições (tabela 1).

Tabela 1. Proposições do Eixo VI - Documento-Referência CONAE/2014

\begin{tabular}{|c|c|c|c|}
\hline Temática & Proposições & Freq. & $\%$ \\
\hline Formação Inicial & $\begin{array}{l}1.2-1.3-1.4-1.7-1.8-1.9-1.11-1.12-1.14- \\
1.18-1.20-1.21-1.22-1.24-1.26-1.29-1.30- \\
1.31-1.32-1.33-2.13\end{array}$ & 21 & $31,3 \%$ \\
\hline Formação Continuada & $\begin{array}{l}1.1-1.2-1.6-1.7-1.8-1.9-1.11-1.12-1.13- \\
1.14-1.15-1.16-1.18-1.19-1.20-1.23-1.25- \\
1.27-1.29-1.30-1.31-1.33-1.34-2.10-2.13\end{array}$ & 25 & $37,3 \%$ \\
\hline Remuneração & $2.1-2.6-2.7-2.8-2.12$ & 5 & $7,5 \%$ \\
\hline Carreira & $\begin{array}{l}1.17-1.28-2.2-2.3-2.4-2.5-2.6-2.7-2.9- \\
2.10-2.11\end{array}$ & 11 & $16,4 \%$ \\
\hline Condições de Trabalho & $1.5-1.10-1.18-1.22-2.6$ & 5 & $7,5 \%$ \\
\hline TOTAL & 67 Proposições & 67 & $100 \%$ \\
\hline
\end{tabular}

Fonte: elaborado pelos autores.

Confirmando as observações de Paro ao analisarmos o conteúdo das referidas proposições, denota-se que a centralidade do documento reside no tema da formação inicial e continuada, que abarca quase $70 \%$ das proposições. Enquanto apenas cinco (ou 7,5\%) se referem à remuneração e 11 (ou 16,4\%) sobre a carreira, ou seja, cerca de $24 \%$ das proposições tratam da carreira e remuneração docente.

Esse fato é mais preocupante ao constatarmos que entre estas proposições sobre remuneração e carreira a maioria se refere ao Piso Salarial Profissional Nacional (PSPN), lei aprovada a mais de cinco anos (2008) e que ainda se encontra envolta em disputas judiciais entre governos e trabalhadores. As condições de trabalho representam apenas cinco (ou 7,5\%) dos itens demonstrando uma preocupação marginal com o tema.

A Confederação Nacional dos Trabalhadores em Educação (CNTE) realizou junto às entidades sindicais levantamento para aferir quais estados cumpriam o PSPN. 
Uma das principais lutas dos trabalhadores da educação brasileira, a Lei Nacional do Piso do Magistério, promulgada em 2008 (Lei 11.738/08), ainda não é respeitada por 07 estados brasileiros. E outros 14 estados não cumprem integralmente a lei, o que inclui a hora-atividade, que deve representar no mínimo $1 / 3$ da jornada de trabalho do professor. Apenas Acre, Ceará, Distrito Federal, Pernambuco e Tocantins cumprem a lei na totalidade (CNTE, 2012).

Este levantamento aponta para as dificuldades objetivas de valorizar o trabalho docente, não apenas nas questões salariais, mas também em melhores condições de trabalho, destacando que cinco anos após a promulgação da lei destinada a garantir condições mínimas de trabalho aos docentes é cumprida apenas por cinco dos 27 entes federados considerando os estados e o DF. Ressalte-se que ainda existe uma situação mais precária nos centenas ou mesmo milhares de sistemas municipais de educação, tradicionalmente com recursos mais escassos e maiores dificuldades técnicas.

Um dos aspectos da lei se refere ao tempo de trabalho do professor que deve ser de no máximo $2 / 3$ com alunos e $1 / 3$ em outras atividades. Nesse aspecto, Freire (1997) destaca a importância do tempo do professor não ser ocupado totalmente ao trabalho em sala de aula, uma vez que a ação do professor envolve múltiplas dimensões para além da interação direta com os alunos.

Apontando para a importância desse debate e também a sua renitência e permanência no embate público, destacamos as contribuições de Freire (2001) ao afirmar que é fundamental ao professor ter sua formação ligada à sua atividade e a seus objetivos, não só como um ato técnico, mas sim na sua dimensão política.

[...] constitui contradição gritante, incoerência clamorosa uma prática educativa que se pretende progressista mas que se realiza dentro de modelos de tal maneira rígidos, verticais, em que não há lugar para a mais mínima posição de dúvida, de curiosidade, de crítica, de sugestão, de presença viva, com voz, de professores e professoras que devem estar submissos aos pacotes; dos educandos, cujo direito se resume ao dever de estudar sem indagar, sem duvidar, submissos aos professores; dos zeladores, das cozinheiras, dos vigias que, trabalhando na escola, são também educadores e precisam ter voz; dos pais, das mães, que são convidados a vir à escola ou para festinhas de fim de ano ou para receber queixas de seus filhos ou para se engajar em mutirões para o reparo do prédio ou até para "participar" de quotas a fim de comprar material escolar... (FREIRE, 2001, p.37-38). 
Freire alertava-nos que a desvalorização salarial estava diretamente vinculada a uma tradição colonial no trato da coisa pública. Portanto, a não valorização salarial dos docentes não está vinculada a falta de recursos financeiros.

É urgente que superemos argumentos como este: "Podemos dar um aumento razoável aos procuradores, pensemos agora ao acaso, porque eles são apenas setenta. Já não podemos fazer o mesmo com as professoras. Elas são vinte mil". Não. Isso não é argumento. O que quero saber primeiro é se as professoras são importantes ou não são. Se seus salários são ou não são insuficientes. Se sua tarefa é ou não é indispensável (FREIRE, 1997, p. 33).

Ao nos debruçarmos sobre as propostas de formação inicial e continuada verificamos que o DR dá ênfase para a educação inclusiva, centrada em propostas de capacitação dos professores e escolas para atuar com a diversidade presente nos sistemas de ensino atual. A maior parte das propostas incluem diferentes temáticas na formação inicial e continuada, como por exemplo, as questões da diversidade sexual, religiosa e cultural, incluindo também a preocupação com os povos das águas, povos da floresta e comunidades quilombolas, além de reafirmar as disposições legais em torno da diversidade étnicorracial, educação indígena e da educação no campo como temáticas a serem atendidas tanto na formação continuada como na formação inicial de professores.

\section{CONCLUSÃO}

Consideramos que uma educação de qualidade pressupõe como condição primeira a valorização docente calcada nos princípios da formação, remuneração, carreira e condições de trabalho. Dessa forma, procuramos nesse trabalho demonstrar que as condições de trabalho envolvem uma série de fatores que favoreçam aos professores e demais funcionários da educação desenvolver um bom trabalho.

Percebe-se que a CONAE se constitui em momento importante de debate sobre os rumos da política educacional em relação a formação e a carreira docente, entretanto, nossa análise aponta para o possível risco de restringir o debate apenas a aspectos técnicos de uma formação burocratizada.

A questão central que se coloca como norte para a valorização docente envolve mais que formação docente, exige mudanças objetivas das condições de trabalho, aspecto obliterado no DR, proposto para a próxima conferência nacional de educação, prevista para ocorrer no início de 2014. 


\section{REFERÊNCIAS}

BRASIL. CONFERÊNCIA NACIONAL DE EDUCAÇÃO (CONAE) 2014. O PNE na articulação do Sistema Nacional de Educação: Participação popular, cooperação federativa e regime de colaboração; Documento Referência. Brasília, DF: FNE, 2012. Disponível em: <http://fne.mec.gov.br/images/pdf/documentoreferenciaconae>. Acesso em: 20 dez. 2012.

CNTE. Saiba quais estados brasileiros não respeitam a Lei do Piso. Disponível em <http://www.cnte.org.br/index.php/comunicacao/noticias/10757-estados-brasileiros-naocumprem-a-lei-do-piso-2.html>. Acesso em: 13 jul. 2013.

FREIRE, P. Professora sim, tia não: cartas a quem ousa ensinar. São Paulo: Editora Olho d’água, 1997.

Educação e mudança. 12a edição. São Paulo: Editora Paz e Terra, 2006.

. Política e educação: ensaios. 5. ed. São Paulo: Cortez, 2001.

HYPOLITO, A. M. Trabalho docente na educação básica no Brasil: as condições de trabalho. In: OLIVEIRA, D. A.; VIEIRA, L. F. (orgs.). Trabalho na educação básica: a condição docente em sete estados brasileiros. Belo Horizonte, MG: Fino Traço, 2012.

MIGLIAVACCA, A. Condições de trabalho do professor. In: OLIVEIRA, D.A.; DUARTE, A.M.C.; VIEIRA, L.M.F. DICIONÁRIO: trabalho, profissão e condição docente. Belo Horizonte: UFMG/Faculdade de Educação, 2010. CDROM.

OLIVEIRA, D.A.; ASSUNÇÃO, A. A. Condições de trabalho docente. In: OLIVEIRA, D. A.; DUARTE, A. M. C.; VIEIRA, L. M. F. DICIONÁRIO: trabalho, profissão e condição docente. Belo Horizonte: UFMG/Faculdade de Educação, 2010. CDROM.

PARO, V. H. Trabalho docente na escola fundamental: questões candentes. Cadernos de Pesquisa, v.42, n.146, p.586-611 maio/ago. 2012.

ROBALINO, M. A saúde e o trabalho na educação da América Latina. Revista Retratos da Escola, Brasília, v. 6, n. 11, p. 315-326, jul./dez. 2012. 